\title{
Literatura da diáspora africana nas Américas: as escritas de Toni Morrison e Conceição Evaristo e alguns de seus desafios para a tradução
}

\author{
Literature of the African diaspora in the Americas: Toni Morrison's and \\ Conceição Evaristo's writings and some of their challenges to translation \\ Marcela Iochem Valente \\ Universidade do Estado do Rio de Janeiro - Rio de Janeiro - Brasil \\ Luciana de Mesquita Silva \\ Centro Federal de Educação Tecnológica Celso Suckow da Fonseca - Rio de Janeiro - Brasil
}

$$
\diamond
$$

\begin{abstract}
Resumo: Este artigo propõe um diálogo entre as literaturas das escritoras Toni Morrison e Conceição Evaristo, partindo dos romances Beloved (1987) e Ponciá Vicêncio (2003), respectivamente, além de discutir alguns aspectos presentes no trabalho das autoras que podem ser percebidos como desafios à tradução. Tal objetivo se baseia no fato de que, embora o continente americano seja um território marcado por uma complexidade no que diz respeito aos povos, tradições, costumes, línguas, entre outros fatores, é possível estabelecer um diálogo entre as diferentes histórias e culturas relativas às Américas se pensarmos na diáspora africana no contexto em questão. Na literatura, Morrison e Evaristo utilizam referentes culturais e/ou variedades dialetais ligados aos povos da diáspora africana com o intuito de trazer a público a história dos afrodescendentes em seus países de origem, história essa geralmente relacionada à escravidão, ao racismo e à busca pela construção de suas identidades.
\end{abstract}

Palavras-chave: Américas; Literatura afro-brasileira; Literatura afro-americana; Desafios; Tradução

\begin{abstract}
This article proposes a dialogue between Toni Morrison's and Conceição Evaristo's literary productions, based on the novels Beloved (1987) and Ponciá Vicêncio (2003), respectively. It also intends to discuss some aspects which are present in the work of these female authors that can be perceived as challenges to translation. This aim is based on the fact that although the American continent is a territory marked by complexity regarding peoples, traditions, customs, languages, among other factors, it is possible to establish a dialogue between the different histories and cultures relative to the Americas if we think about the African diaspora in the referred context. In literature, Morrison and Evaristo use cultural references and/or dialectal varieties linked to the peoples of the African diaspora in order to publicize the history of Afro-descendants in their home countries. This history is generally related to slavery, racism and the search for the construction of their identities.
\end{abstract}

Keywords: Americas; Afro-brazilian literature; African-american literature; Challenges; Translation

\section{Introdução}

Ao refletirmos sobre o continente americano, geralmente iremos nos deparar com um cenário repleto de multiplicidades no que diz respeito aos povos, às tradições, aos costumes, às línguas, entre outros aspectos. Apesar disso, é possível voltarmos ao passado e procurarmos estabelecer um diálogo entre as diferentes histórias e culturas relativas às Américas. Uma das formas em que tal diálogo pode ser observado se relaciona com a forte presença da diáspora africana no continente em questão.
Retirados de forma violenta de sua terra natal, os africanos foram trazidos em condições desumanas para as Américas entre os séculos XVI e XIX. Nesse processo de escravização, cujo objetivo era gerar lucro para nações europeias, os filhos da África tiveram suas histórias silenciadas, quando não aniquiladas, pela cultura hegemônica. Dessa forma, uma vez rompidos os laços com seu território de origem, os negros africanos buscaram encontrar maneiras de reconstruir suas próprias identidades e atuar na formação de uma memória cultural. 
É importante ressaltar que essas vozes de tempos longínquos continuam a ecoar até os dias de hoje nos mais diferentes campos como a música, a política e a literatura. No contexto da diáspora africana nas Américas, sujeitos que estiveram por muito tempo relegados a uma condição de marginalidade procuram se fazer ouvir em um mundo ainda dominado por uma supremacia branca europeia. Como exemplos dessa postura relutante, especificamente no que diz respeito ao universo literário, podemos mencionar as escritoras Toni Morrison e Conceição Evaristo.

Tanto a escrita de Morrison, afro-americana, como a de Evaristo, afro-brasileira, apresentam como marca o desejo de dar visibilidade à história dos afrodescendentes em seus países de origem. Torna-se necessário destacar que a história desses povos se caracteriza, de forma geral, pela escravidão, pelo preconceito racial e por uma tentativa de construção de sua própria identidade. Desse modo, as autoras lançam mão de referentes culturais e/ ou variedades dialetais ligados à diáspora africana para compor suas obras. Tais particularidades são mencionadas por Edwin Gentzler, importante teórico dos Estudos da Tradução, no artigo "Translation Without Borders":

A matriz das metáforas que inspiram a escrita criativa afro-brasileira-caribenha-americana está fortemente relacionada ao espaço da tradução - os cruzamentos, passagens, interseções, limites e, inevitavelmente, o limbo, o espaço liminar entre os mundos material e espiritual. Fluidez, transição e mudança se tornam mais a norma do que a exceção; a linguagem passa continuamente por processos de interpretação, tradução e reconfiguração (2014, s.n.p. - tradução nossa).

Nesse sentido, o presente artigo tem como objetivo não só abordar o diálogo entre as literaturas de Toni Morrison e de Conceição Evaristo, mas também discutir alguns aspectos presentes no trabalho das autoras que podem ser vistos como desafios à tradução. Para desenvolvermos nossa análise, selecionamos os romances Beloved (1987), de Morrison, e Ponciá Vicêncio (2003), de Evaristo, tendo em vista o fato de se tratarem de obras relevantes nas carreiras literárias de ambas as escritoras.

\section{Toni Morrison e Conceição Evaristo: escrita, luta, resistência}

A escritora afro-americana Toni Morrison (Chloe Ardelia Wofford) nasceu em Lorain, Ohio, nos Estados Unidos, em 1931. Desde cedo, Morrison costumava ouvir histórias baseadas no folclore africano e em contos estadunidenses e europeus que eram transformados a partir da inserção de elementos específicos da cultura afro-americana (GATES e McKAY, 1997), além de ser incentivada ao hábito da leitura. Ela se formou em Inglês na Howard University, uma universidade tradicionalmente negra, situada em Washington D.C., em 1953, e fez mestrado na mesma área na Cornell University, em Ithaca, Nova York, desenvolvendo uma pesquisa sobre a alienação e o suicídio nas obras de William Faulkner e Virginia Woolf, cujos estilos literários a influenciaram posteriormente em sua carreira como escritora.

Depois de lecionar na Texas Southern University e na própria Howard University, Morrison foi contratada pela editora Random House em 1968 com o propósito de editar trabalhos de autores majoritariamente negros. Nesse caso, além de trazer grandes contribuições para a divulgação da cultura afro-americana, a partir da publicação de um número considerável de obras de autores como Angela Davis, Toni Cade Bambara e Gayl Jones, ela exerceu um papel muito importante na formação do cânone desse campo de estudos. Um dos projetos organizados por Morrison e quatro outros editores - The Black Book (1974) - aborda a trajetória de vida de descendentes de africanos em solo estadunidense, através de fotos, receitas, cartas, certidões de nascimento e recortes de jornal. Ao procurar materiais para a composição desse livro, Morrison encontrou a história de Margaret Garner que, após fugir da propriedade onde era mantida como escrava e tentar ser recapturada, assassinou sua própria filha para que a mesma não se submetesse à escravidão. Esse episódio serviu de inspiração para a escrita de seu romance Beloved, publicado 23 anos mais tarde.

Paralelamente à ocupação de editora na Random House, onde trabalhou até 1983, Morrison mantinha sua carreira como professora universitária, além de escrever seus próprios textos. Sua escrita apresenta uma multiplicidade de influências, como obras das autoras Eudora Welty e Marguerite Duras, romances latino-americanos e, sobretudo, fontes africanas e afroamericanas. Nas palavras de Morrison, sua literatura contribuiu de modo inovador para o campo da literatura produzida por negros nos Estados Unidos, na medida em que "[n]enhum escritor afro-americano jamais fez o que eu fiz, que foi escrever sem o olhar atento dos brancos" (MORRISON, apud HOUSTON, 2005, p. 253 - tradução nossa).

Morrison tem produzido uma variedade de gêneros ao longo dos anos, incluindo romances - The Bluest Eye (1970), Sula (1973), Song of Solomon (1977), Tar Baby (1981), Beloved (1987), Jazz (1992), Paradise (1998), Love (2003), A Mercy (2008) e Home (2012) - pelos quais a autora é mais conhecida, bem como literatura infantil, conto, ensaios, livros de crítica literária e peças teatrais. Tamanha produção tem lhe rendido uma variedade de prêmios literários, tais como o Pulitzer Prize por 
Beloved (1988) e o Prêmio Nobel de Literatura (1993), e uma multiplicidade de línguas para as quais seus livros têm sido traduzidos. Entre elas estão o português, o espanhol, o alemão e o francês.

É importante ressaltar que, com relação aos seus romances, eles apresentam uma forma peculiar de narrativa, a partir de técnicas de fluxo de consciência, múltiplas perspectivas e cronologia não-linear. Os personagens são, em grande parte, negros e, através deles, a autora revela as lutas individuais e coletivas dos afro-americanos em uma sociedade hegemônica branca. Na visão de Morrison, quando ela começou a escrever, sentiu a necessidade de destacar a realidade do povo negro, tradicionalmente omitido da história oficial, com o objetivo de ler algo que ainda não havia sido escrito (MORRISON, apud RUSHDIE, 1992). Outra característica marcante em sua escrita é o uso de uma linguagem que busca evidenciar a tradição oral pertinente ao contexto afro-americano.

A literatura de Morrison ilustra o pensamento de Henry Louis Gates, Jr., em The Signifying Monkey: A Theory of African American Literary Criticism (1989). Nesse livro, Gates amplia o cenário da crítica literária ao propor uma teorização que ilumina uma tradição negra estadunidense marcada, ao mesmo tempo, por uma relação e por uma subversão de valores dominantes brancos. Assim, o autor afirma que, "[e]nquanto escritores negros com toda a certeza revisitam textos da tradição ocidental, eles procuram fazê-lo frequentemente 'de um modo autêntico', com uma diferença negra, uma noção forte de diferença baseada no vernáculo negro" (GATES, 1989, p.xxii - tradução nossa). Em tal contexto, os textos dialogam entre si e apresentam como peculiaridade um trabalho com a linguagem que pretende ser caracteristicamente afro-americana, a partir, por exemplo, do uso de palavras que adquirem nova significação e de estruturas gramaticais, lexicais e fonológicas específicas.

Dessa forma, as obras de Morrison, incluindo Beloved, se propõem a valorizar o ato de se contar histórias, enfatizar a necessidade de participação do leitor na construção do enredo de suas narrativas e lançar mão de referências à música. Ao tentar "[m]isturar o vernáculo coloquial e a variedade padrão" (HACKNEY, 1996, p. 131 - tradução nossa) da língua inglesa, além de trazer à tona aspectos do African American English, dialeto falado por parte da população negra dos Estados Unidos, Morrison pretende captar diferentes formas de expressão dessa comunidade, o que acaba se tornando um grande desafio para a tradução.

No que diz respeito à escritora afro-brasileira Conceição Evaristo, ela nasceu em Belo Horizonte, em 29 de novembro de 1946, em uma família humilde, vivendo em uma favela na zona sul da capital mineira. Para ajudar a família, "[a]os oito anos surgiu seu primeiro emprego doméstico e ao longo dos anos, outros foram acontecendo. Conceição Evaristo também participou com sua mãe e tia da lavagem, do apanhar e do entregar trouxas de roupas nas casas das patroas" (LIMA, 2009, p. 53). Nesse cenário de grandes dificuldades financeiras, Evaristo aprendeu a escrever e a ler. Como relata em "Da grafiadesenho de minha mãe, um dos lugares de nascimento de minha escrita" (2007), a escritora recorda que "as mãos de lavadeira de sua mãe guiaram os [seus] dedos no exercício de copiar [seu] nome, as letras do alfabeto, as sílabas, os números, os difíceis deveres de escola, para crianças oriundas de famílias semi-analfabetas" (p. 18).

Em sua tese $O$ comprometimento etnográfico afrodescendente das escritoras negras Conceição Evaristo \& Geni Guimarães (2009), Omar da Silva Lima comenta que a relação de Evaristo com a literatura vem desde cedo, ainda em seus tempos de escola primária (o que hoje chamamos de ensino fundamental). Segundo Lima, "[a]o terminar o primário, em 1958, Conceição Evaristo ganhou o seu primeiro prêmio de literatura, vencendo um concurso de redação" (p. 54), escrevendo de forma notável e bela sobre o orgulho de ser brasileira. A própria autora também revela que sua adolescência foi marcada por um diário, por sensíveis redações e, ainda, por pequenos contos e poesias, material que se perdeu ao longo do tempo: "[r]asguei, queimei, joguei fora" (p. 154).

Mesmo em meio a grandes dificuldades, Evaristo optou por estudar e, enquanto trabalhava como doméstica, conseguiu concluir seu curso normal em sua cidade. Por não conseguir lecionar em Minas após estar formada, ela migrou para o Rio de Janeiro em 1973 e foi aprovada em concurso público para o magistério na cidade de Niterói, dois anos depois. Optando pelas letras, em 1976, Evaristo ingressou em seu curso superior na Universidade Federal do Rio de Janeiro; posteriormente, em 1992, em seu mestrado em Literatura Brasileira na Pontifícia Universidade Católica do Rio de Janeiro, onde em 1996 defendeu a dissertação Literatura Negra: uma poética da nossa afro-brasilidade; e em 2011, concluiu o seu doutorado em Literatura Comparada na Universidade Federal Fluminense, defendendo a tese intitulada Poemas malungos: cânticos irmãos.

Quanto a sua produção, Evaristo possui contos e poemas publicados na série Cadernos Negros, e foi através de seus poemas nessa série que a escritora começou a ser conhecida no contexto de literatura afro-brasileira. Além de sua poesia, contos e de seus trabalhos acadêmicos publicados, Evaristo é autora de dois romances: Ponciá Vicêncio (2003) e Becos da Memória (2006), ambos publicados pela editora Mazza, sendo que o primeiro foi traduzido para o inglês em 2007 pela editora Host, nos Estados Unidos, e foi recentemente lançado em 
francês, em março de 2015, no Salão Internacional do Livro em Paris, pela editora Anacaona. Em 2008, Evaristo lançou uma coletânea que reúne uma série de poemas anteriormente publicados nos Cadernos Negros sob o título Poemas da recordação e outros movimentos, pela editora Nandyala; em 2011, publicou uma coletânea de contos intitulada Insubmissas lágrimas de mulheres pela mesma editora; e em março de 2015, lançou o seu mais recente livro, mais uma coletânea de contos, intitulada Olhos d'água, pela editora Pallas.

Segundo Lima, a publicação da tradução em língua inglesa de Ponciá Vicêncio "torna Conceição Evaristo a segunda escritora afro-brasileira a ter uma obra publicada em terras estrangeiras. A primeira foi Carolina Maria de Jesus com o seu Quarto de despejo: diário de uma favelada" (2009, p.57). Cabe lembrar que diversos poemas de Evaristo já estão traduzidos para a língua inglesa como consequência da recente tradução dos Cadernos negros, Black Notebooks (2008); seu conto "Maria" também foi traduzido em 1995, publicado no volume 18 da revista Callaloo; o conto "Ana Davenga" foi traduzido e publicado na coletânea Fourteen Female Voices From Brazil em 2002; "Duzu-Querença" foi publicado na coletânea bilíngue Women Righting: AfroBrazilian Women's Short Fiction, editada por Mirian Alves e Maria Helena Lima em 2005; e um excerto de seu segundo romance, Becos da memória, foi publicado em inglês em 2007 no volume 30 da revista Callaloo, sob o título "Ditinha".

Em sua obra, Evaristo busca valorizar a cultura afro-brasileira, desvelando aspectos por muito tempo marginalizados e/ou branqueados por relatos hegemônicos de nossa História. Evaristo aborda questões como o ser negra e pobre no Brasil com um olhar diferenciado, trazendo também a sua vivência para a sua ficção, o que a autora chama de escrevivência, e desconstruindo o mito da democracia racial por muito tempo predominante em nosso país. Através de sua obra e de sua postura crítica, Evaristo busca subverter a posição marginal a que o negro foi relegado ao longo de nossa história.

No Salão Internacional do Livro em Paris, em março de 2015, onde Evaristo foi bastante assediada e reconhecida por seu romance Ponciá Vicêncio, cuja tradução para o francês foi lançada durante o evento (L'histoire de Poncia), a autora afirmou que o "[seu] caso chama a atenção porque não é muito comum uma escritora brasileira negra participar de uma feira internacional. A gente fica como fruta rara. (...) a presença negra fora das instâncias em que se está acostumado a vê-la causa furor (...) não seria a mesma coisa se isso aqui fosse um festival de gastronomia em que baianas estivessem preparando acarajés." (EVARISTO, apud NEVES, 2015, s.n.p.). Através de tal posicionamento, a autora dá voz à população negra em nosso país, contando histórias antes caladas e valorizando elementos culturais antes apagados ou deixados à margem. Embora em português não haja nenhum aspecto linguístico como o African American English, presente na literatura de Morrison, Evaristo traz em sua obra diferentes formas de expressão da comunidade afro-brasileira, com uma enorme riqueza de elementos culturais específicos, o que acaba sendo um desafio para a tradução.

\section{Beloved e Ponciá Vicêncio: memórias de sujeitos negros nas Américas}

Beloved é o quinto romance de Toni Morrison. Considerado atualmente um clássico não só da literatura afro-americana, como também do contexto literário estadunidense como um todo, seu enredo é inspirado em fatos reais: a história de Margaret Garner, uma escrava fugitiva de Kentucky que, em 1856, tentou matar seus próprios filhos após ser recapturada em Ohio, estado livre da escravidão ${ }^{1}$. Um deles, uma menina de dois anos, veio a falecer. Morrison baseou-se nesse episódio trágico para criar um texto ficcional, mostrando-se consciente de tamanho desafio: "[n]ão há linguagem. E você tem que tê-la. Ou tentar. Sempre falha" (MORRISON, apud BROCKES, 2012, s.n.p. - tradução nossa).

Beloved se passa no período pós Guerra Civil estadunidense, entre 1873 e 1875. Nessa época, apesar de a escravidão ter sido abolida em todo o país, prevalecem as perseguições, os linchamentos e os atos violentos de brancos contra negros. Sethe Suggs vive atormentada pelas lembranças de um acontecimento traumático. Em 1855, depois de fugir da propriedade em que era mantida como escrava, em Kentucky, e permanecer escondida durante 28 dias na casa de Baby Suggs, sua sogra, em Ohio, ela foi encontrada e obrigada a retornar para os seus donos. Diante disso, em uma atitude de desespero, ela cometeu o homicídio de sua filha mais velha (e tentou fazer o mesmo com os outros: Howard, Buglar e a recém-nascida Denver), cortando seu pescoço com um serrote. Em seu túmulo, pediu que fosse escrita a palavra "B-e-l-o-v-e-d" ("amada"). Sethe foi presa pelo assassinato e, após cumprir sua sentença, voltou a morar com Baby Suggs.

Aos 13 anos de idade, Sethe tinha sido comprada pela família Garner, proprietária da fazenda Sweet Home (“doce lar"), para substituir Baby Suggs, cuja liberdade havia sido adquirida após o trabalho incansável de seu filho Halle. Na visão de Sethe, única mulher da propriedade além da Sra. Garner, aquele local era um paraíso no qual

\footnotetext{
Segundo o Fugitive Slave Act (1850), os proprietários de escravos teriam o direito de recapturá-los caso os mesmos fugissem e fossem encontrados em estados em que a escravidão já tivesse sido abolida (Wisker, 2000).
} 
ela podia viver tranquilamente com seu marido, Halle, e seus três filhos, mesmo estando submetidos ao regime de escravidão. Isso porque "[o]s Garner, parecia-lhe, tinham um tipo especial de escravidão, tratavam os escravos como trabalhadores pagos, ouviam o que diziam, ensinavam o que queriam que soubessem" (MORRISON, 2007, p. 193). O Sr. Garner, portanto, era considerado um senhor benevolente, que via os escravos como humanos, não os chicoteava, oferecia-lhes boa alimentação e permitia que eles utilizassem armas para caçar. No entanto, esse cenário foi completamente modificado após a morte do $\mathrm{Sr}$. Garner e a chegada de Schoolteacher, novo administrador da Sweet Home.

Seu modo de lidar com os escravos era cruel, a começar pelo fato de ensinar aos seus sobrinhos que os negros tinham características humanas e animais. Para demonstrar sua teoria, ele costumava medir partes de seus corpos e contar seus dentes. Além disso, batia neles e os maltratava. Tal postura violenta de Schoolteacher foi determinante para um plano de fuga arquitetado por Halle, Paul A, Paul D, Sixo e Sethe, que estava grávida de Denver e ainda amamentava sua filha mais velha. Após decidirem como escapariam da fazenda, Sethe foi abusada sexualmente pelos sobrinhos de Schoolteacher: "[a]queles rapazes entraram lá e tomaram meu leite. Foi para isso que eles entraram lá. Me seguraram e tomaram" (p. 35). Ela contou o ocorrido para a Sra. Garner e os rapazes acabaram descobrindo o que ela fez. Diante disso, Schoolteacher mandou um deles chicoteá-la, ato que deixou uma marca profunda em suas costas.

Traumatizada, Sethe se encorajou ainda mais para fugir, conforme combinado. Primeiramente, mandou os três filhos em uma caravana de negros que também estavam fugindo para que eles fossem entregues a Baby Suggs. Ela planejava ir posteriormente, após encontrar Halle. Entretanto, ele não apareceu, talvez porque tenha ficado louco ao ver a cena de estupro de sua esposa, sem que ela percebesse. Os outros também não, já que Paul A foi capturado e enforcado; Paul D, castigado com um freio de ferro na boca e vendido em seguida; e Sixo, queimado até a morte. Sethe foi a única que conseguiu concretizar o objetivo do grupo, partindo da Sweet Home em direção ao rio Ohio. Lá, foi ajudada por uma menina branca, Amy Denver, que cuidou de sua ferida nas costas, “[u]ma árvore de arônia. [...] Florindo" (p. 115) e a auxiliou no parto de Denver. Depois de algum tempo, Sethe conseguiu chegar à casa de Baby Suggs e reunirse novamente com seus filhos. Todavia, foi encontrada por Schoolteacher aproximadamente um mês depois e cometeu o assassinato de sua filha mais velha, como foi citado anteriormente.

Passaram-se dezoito anos. Somente Sethe e Denver moram na casa situada na Bluestone Road, número 124.
Howard e Buglar tinham fugido aos 13 anos de idade e Baby Suggs havia falecido há algum tempo. O local é assombrado por um fantasma, Beloved, que Sethe e Denver acreditam ser o espírito da menina assassinada. Tal é a frase que abre o romance, cuja estrutura não segue uma ordem cronológica dos acontecimentos: “[o] 124 era rancoroso. Cheio de um veneno de bebê" (p. 17). Nesse ambiente, ouvem-se vozes estranhas e tremores violentos, o que causa uma ruptura na rotina diária de mãe e filha.

Certo dia, Sethe está na varanda de sua casa e avista Paul D, que se aproxima e começa a se lembrar de algumas histórias do passado. Ele conta, por exemplo, que na última vez que viu Halle, ele estava fora de si, lambuzando seu rosto com manteiga. No decorrer da conversa, Denver chega e diz a Paul D que havia um fantasma na casa e que o mesmo era de sua irmã, a qual havia morrido ali. Após algum tempo, a casa começa a tremer e Paul D grita palavras de ordem: "[d]eixe este lugar em paz! Saia daqui!" (p. 37). Depois desse dia, Paul $\mathrm{D}$ e Sethe começam um relacionamento, mas Beloved acaba manipulando e seduzindo o namorado de sua mãe.

Além disso, Beloved consome Sethe cada dia mais: ela perde o emprego e a comida começa a faltar em casa. Ao testemunhar a gravidade da situação, Denver procura ajuda no bairro e consegue que um grupo de mulheres se dirijam à sua casa para tentar explusar Beloved de lá. Ao se aproximarem, cantando, Sethe e Beloved vão até a porta: "as mulheres cantoras reconheceram Sethe de imediato e se surpreenderam com a ausência de medo em si próprias quando viram o que estava parado ao lado dela. A criança-diabo era esperta, pensaram. E linda" (p. 346). Beloved desaparece e Sethe se recupera gradativamente, reconciliando-se com Paul D.

Em Beloved, Morrison faz uma releitura das slave narratives, confirmando a ideia proposta por Gates (1989) de que os textos na literatura afro-americana dialogam entre si. Mas ela a realiza a partir de uma perspectiva que se contrapõe ao silenciamento imposto a essas obras no que se refere aos elementos negativos inerentes à escravidão. Isso porque tal silenciamento está vinculado ao fato de as slave narratives geralmente serem direcionadas aos interesses de um público leitor formado por brancos. Embora haja pouca incidência de aspectos relativos ao African American Engish, Beloved aborda uma temática peculiar do universo afro-americano, apresentando um enredo que enfoca os efeitos do sistema escravista na identidade da mulher negra, representada por Sethe.

Ponciá Vicêncio, por sua vez, nos apresenta a trajetória da protagonista que dá nome ao romance, uma mulher negra e descendente de escravos, desde sua infância no campo, passando pela idade adulta na cidade grande, até o seu retorno às terras de origem. O romance, também com cronologia não-linear, apresenta flashes da 
experiência de vida da protagonista Ponciá, de seu irmão Luandi e de sua mãe Maria Vicêncio. Mulher oriunda do mundo rural, Ponciá teve que aprender a lidar com grandes perdas durante sua vida: seu avô e pai falecidos, mãe e irmão desaparecidos, sete filhos gerados e perdidos.

Ponciá é neta de escravos e filha de um homem beneficiado pela Lei do Ventre Livre. Enquanto a menina e sua mãe Maria Vicêncio cuidam dos afazeres domésticos e dos utensílios de barro que produzem para vender nas proximidades da Vila Vicêncio, onde moram, seu pai e seu irmão trabalham na lavoura, ficando dias longe de casa. "Ponciá Vicêncio se lembrava pouco do pai. O homem não parava em casa. Vivia constantemente no trabalho da roça, nas terras dos brancos" (EVARISTO, 2006, p. 17). As terras em que Ponciá e sua família viviam pertenciam ao coronel Vicêncio.

As terras tinham sido ofertas dos antigos donos, que alegavam ser presente de libertação. E, como tal, podiam ficar por ali, levantar moradias e plantar seus sustentos. Uma condição havia, entretanto, a de que continuassem todos a trabalhar nas terras do Coronel Vicêncio. (p. 48)

Já adulta, após a morte repentina de seu pai e insatisfeita com a falta de perspectiva da vida que levava, Ponciá decide buscar uma vida melhor para si na cidade grande. A menina junta então suas poucas economias e compra uma passagem de trem para a cidade, viagem que dura cerca de três dias.

$\mathrm{Na}$ cidade, após dificuldades iniciais e uma noite junto a mendigos na porta da igreja, Ponciá chega a desejar sua volta ao campo: "[d] esejou estar no trem, estar de volta. Escondeu o rosto sobre a trouxa que estava no colo e bem baixo, quase silenciosamente, quase escondida de si própria, chorou" (p. 41). Ainda na igreja, na manhã seguinte, Ponciá consegue um emprego como empregada doméstica, "ia aprendendo muito bem. Estava de coração leve, achava que a vida tinha uma saída. Trabalharia, juntaria dinheiro, compraria uma casinha e voltaria para buscar a mãe e o irmão. A vida lhe parecia possível e fácil" (p. 43). Depois de muitos anos, Ponciá finalmente consegue comprar um quartinho em um morro na periferia da cidade grande e volta ao povoado em busca de sua mãe e seu irmão, porém depara-se com a casa vazia. De volta à cidade, sem esperanças e motivações já que "[t]rabalhara, conseguira juntar algum dinheiro com o qual pudera comprar uma casinha, mas faltava-lhe os seus" (p. 74) Ponciá conhece um homem trabalhador na construção civil, com quem acaba vivendo uma relação infeliz e complexa, com muitos episódios de violência e com a perda dos sete filhos que gerou."Lá estava ela agora com seu homem, sem filhos e sem ter encontrado um modo de ser feliz" (p. 54) com um companheiro que "por qualquer coisa lhe enchia de socos e pontapés" (p. 55). Assim, em sua busca por uma vida melhor, Ponciá acaba em condições degradantes, vivendo em uma favela acompanhada de um homem que não a compreendia.

Encorajado pela atitude da irmã, Luandi também parte para a cidade grande, mas acaba perdendo o endereço de Ponciá e, assim, o seu drama pessoal ganha tonalidade maior em parte do romance. $\mathrm{Na}$ estação ferroviária, sem rumo em sua primeira noite na cidade, Luandi é acordado por um policial e, por portar um canivete, é conduzido à delegacia. Ali surge um fio de esperança em Luandi que "[a]cabava de fazer uma descoberta. A cidade era mesmo melhor do que na roça. Ali estava a prova. O soldado negro! Ah! que beleza! Na cidade, negro também mandava!" (p. 70). Foi nessa delegacia que Luandi conseguiu seu primeiro emprego na cidade, como faxineiro. Foi ali também que ele encontrou esperança e um ídolo, o soldado Nestor, negro como ele.

Assim como sua irmã, Luandi volta à Vila Vicêncio para reencontrar a mãe e na esperança de ter notícias de Ponciá, mas, assim como a irmã, retorna sem informação alguma. Na esperança de que elas ainda voltassem à Vila Vicêncio, deixa seu endereço com alguns conhecidos no povoado. Na cidade, Luandi aprende a ler e a escrever com o soldado Nestor e apaixona-se por Bilisa, uma prostituta que acaba sendo assassinada por seu gigolô, Negro Climério. A profunda tristeza de Luandi devido à morte de Bilisa só é amenizada pelo reencontro com sua mãe que, depois de anos, resolve ir em busca de seus dois filhos na cidade.

Quando Maria Vicêncio chegou à estação na cidade, soldado Nestor estava de serviço lá "[e] quando a mãe de Ponciá e Luandi entregou ao soldado Nestor um papelzinho dobrado, quase rasgado pelo tempo e que ela cuidadosamente guardava enrolado num pedacinho de pano, entre os seios, ele sorriu reconhecendo a própria letra" (p. 116). O reencontro de Luandi com sua mãe o ajudou a se recuperar da perda de Bilisa e a continuar em busca de seu sonho de se tornar soldado, que já estava próximo de se tornar realidade. Seu primeiro dia de trabalho como soldado foi na estação ferroviária "e eis que, de repente, capta a imagem de uma mulher que ia e vinha, num caminho sem nexo, quase em círculo, no lado oposto em que ele se encontrava" (p. 123). Era Ponciá. E ali, na estação ferroviária, encerra-se a busca de Luandi pelos seus.

Após o reencontro da família, Luandi percebe que seu sonho de ser soldado e poderoso era, na verdade uma ilusão, já que "[a]penas cumpria ordens, mesmo quando mandava, mesmo quando prendia" (p. 126). Assim, a cidade idealizada pela família Vicêncio como o local onde teriam possibilidade de uma vida em melhores 
condições foi pouco a pouco sendo desconstruída, e os sonhos trazidos pela família foram se perdendo. Todos acabaram vivendo sob condições tão degradantes quanto as que viviam no campo e, já sem esperanças, acabaram voltando à sua terra de origem.

Através de uma narrativa fragmentada, recheada de frases entrecortadas e com constantes flashbacks, o romance promove uma articulação entre presente e passado, poesia e sofrimento, vivências e memórias. Ao longo da construção da protagonista, percebemos que a memória da infância inocente e de boas recordações da menina vivendo no campo vai sendo substituída pela memória da adolescente negra, empregada doméstica, insatisfeita com sua realidade e, ainda, da mulher que deixou a família e as terras de origem em busca de uma vida melhor na cidade grande, porém acabou vivendo em condições tão degradantes quanto às que vivia no campo, sofrendo violências do seu companheiro e perdida dos seus e de si mesma.

\section{Alguns desafios para a tradução de Beloved e de Ponciá Vicêncio}

Conforme mencionamos anteriormente, a linguagem relativa à literatura da diáspora negra geralmente se constitui como desafio para a tradução, uma vez que apresenta características que pretendem aludir ao universo da população afrodescendente, historicamente massacrada e inferiorizada. José Rubens Siqueira, um dos tradutores de Beloved no Brasil ${ }^{2}$, ressalta esse cenário ao afirmar que os personagens nas obras de Toni Morrison "[s]ão entranhadamente negros. Em sua condição pessoal e social. E me é muito prazeroso traduzir seu uso da língua que é pessoal, bem particular" (SIQUEIRA apud SILVA, 2015, p. 202).

No caso de Beloved, especificamente, há uma variedade de exemplos que ilustram esse cenário tipicamente afro-americano através de aspectos como referentes culturais, variedades dialetais, entre outros. Entre eles pode ser citado o sermão da personagem Baby Suggs, considerada uma espécie de líder na comunidade em que vivia:

"Here," she said, "in this here place, we flesh; flesh that weeps, laughs; flesh that dances on bare feet in grass. Love it. Love it hard. Yonder they do not love your flesh. They despise it... No more do they love the skin on your back. Yonder they flay it. And O my people they do not love your hands. Those they only

\footnotetext{
2 Beloved tem duas traduções no Brasil, ambas com o título de Amada: a primeira foi feita por Evelyn Kay Massaro e publicada em 1989 pela editora Best Seller e em 1993 pela Círculo do Livro, enquanto que a segunda foi realizada por José Rubens Siqueira e lançada em 2007 e em 2011 pela editora Companhia das Letras.
}

use, tie, bind, chop off and leave empty. Love your hands! Love them! Raise them up and kiss them [...]. (MORRISON, 2004, p. 103)

$\mathrm{Na}$ passagem em questão, Baby Suggs convida seus seguidores a amarem os seus corpos, corpos esses marcados por traumas e memórias da escravidão. A forma como a personagem se dirige ao seu povo ilustra o call and response, técnica através da qual o emissor conduz os receptores a interagirem com seu discurso, transformando-os em agentes que participam do jogo de linguagem criado e orientado por ele. Além dessa característica peculiar da cultura afro-americana, o trecho em análise apresenta outros pontos que podem ser vistos como desafio à tradução: a transformação do substantivo "flesh" ("carne", em português) em verbo ("we flesh"), o uso de ain't no lugar de aren't em "they ain't in love with your mouth" e a grafia da palavra "leavings" como "leavins".

O personagem Paul D também traz vida aos afroamericanos ao entoar canções que faziam parte do trabalho dos escravos na construção de ferrovias no sul dos Estados Unidos. Uma delas é "Trouble in Mind":

Lay my head on the railroad line,/ Train come along, pacify my mind/ If I had my weight in lime,/ I'd whip my captain till he went stone blind./ Five-cent nickel,/ Ten-cent dime,/ Busting rocks is busting time. (MORRISON, 2004, p. 48)

É importante observar que, na letra dessa música, há referências à escravidão como um sistema ao qual os negros resistiam, uma vez que prefeririam deitar suas cabeças nos trilhos e deixar o trem passar para que sua aflição tivesse fim, além de mostrarem um sentimento de vingança a tudo o que sofriam por meio de seu desejo de chicotear seus algozes até ficarem cegos.

Soma-se a Baby Suggs e Paul D a personagem que dá título ao romance de Morrison. Beloved apresenta uma fala que mistura o inglês padrão e outras variantes da língua inglesa. Em uma de suas aparições no 124, ela se dirige a Denver, sua irmã, e pergunta sobre Sethe, sua mãe: "Your woman she never fix up your hair?" (MORRISON, 2004, p. 72). Sethe não compreende a fala de Beloved e questiona: "My woman? You mean my mother?" (p. 72). Essa passagem demonstra a diferença entre a linguagem de Beloved e de Sethe, diferença essa que representa a multiplicidade de variedades linguísticas existentes na comunidade afro-americana.

Com relação a Sethe, ela é uma das personagens, além de Paul D, que se valem do African American English em suas falas. Em uma conversa com Paul D sobre a origem da cicatriz em suas costas, que lembra o desenho de uma árvore, Sethe explica o seguinte: 


\begin{abstract}
"After I left you, those boys came in and took my milk. That's what they came for. Held me down and took it. I told Mrs. Garner on em. She had that lump and couldn't speak but her eyes rolled out tears. Them boys found out I told on em. Schoolteacher made one open up my back, and when it closed it made a tree. It grows there still."

"They used cowhide on you?"

"And they took my milk."

"They beat you and you was pregnant?"

“And they took my milk!" (MORRISON, 2004, p. 19-20)
\end{abstract}

No trecho acima, o uso de "them" em "Them boys found out I told on em", em vez de "they", além da ausência do verbo auxiliar "did" no início de perguntas como "They used cowhide on you?" e "They beat you and you was pregnant?", demonstram a preferência pelo African American English em detrimento do inglês padrão. Desse modo, características como as citadas se propõem como uma tentativa de promover visibilidade à cultura afro-americana, gerando grandes desafios para a tradução.

Enquanto o African American English é geralmente representado em obras afro-americanas com base em questões políticas, ideológicas e outras, no Brasil, não podemos falar em uma linguagem específica utilizada por afrodescendentes. Embora tenhamos conhecimento da obra O português afro-brasileiro, livro organizado por Dante Lucchesi, Alan Baxter e Ilza Ribeiro, publicado em 2009 , fruto de uma pesquisa sobre a linguagem utilizada em comunidades rurais isoladas no interior da Bahia, predominantemente habitadas por afrodescendentes, no Brasil, não há uma variedade linguística relacionada apenas à questão étnica, com implicações ideológicas, como ocorre no contexto estadunidense.

No entanto, a produção da escritora afro-brasileira Conceição Evaristo é recheada de referências culturais características não apenas do Brasil como um todo, mas, principalmente, da comunidade afro-brasileira. Além disso, Evaristo utiliza uma linguagem poética, criativa, com uma seleção vocabular muito cuidadosa e até mesmo, algumas vezes, com a construção de novos vocábulos para alcançar os efeitos desejados em sua escrita.

Embora Ponciá Vicêncio seja um romance, em prosa, narrado em terceira pessoa e utilizando a variedade linguística padrão da língua portuguesa do Brasil, a escrita criativa de Evaristo se faz presente. Somando-se à linguagem poética do romance e a seleção vocabular cuidadosa feita pela autora, também é de grande relevância a forte presença de peculiaridades regionais e o forte apelo aos sentidos que ocorre a partir de imagens, sabores e odores também bastante peculiares do Brasil, mais especificamente de regiões do interior do país.
As casas das terras dos negros, para o olhar estrangeiro, eram aparentemente iguais. Chão batido, liso, escorregadio, paredes de pau-a-pique e cobertura de capim. As camas dos adultos e das crianças eram jiraus que os homens e mesmo as mulheres armavam com galhos de arvore amarrados com cipós. O colchão de capim era, às vezes, cheiroso, dado ao alecrim que se misturava ali dentro na hora de sua feitura. Os grandes vasilhames de barro ou ferro e os tachos onde as mulheres faziam doces permitiam imaginar farturas. As crianças gostavam de raspar os tachos se lambuzando com os doces de mamão, cidra, banana, goiaba, leite, abóbora e o melado de rapadura. (p. 59)

Sentiu o cheiro de biscoito frito, de café fresco dado para as mulheres e as crianças que estavam fazendo quarto ao defunto. Sentiu também o cheiro de pinga que exalava da garrafinha e da boca dos homens sentados lá fora com o chapéu no colo. (p. 15)

Nos dois fragmentos anteriormente apresentados é notável a presença desses elementos tipicamente brasileiros que comentamos. Um leitor que não tenha um pouco de conhecimento da nossa cultura terá grande dificuldade para compreender e visualizar alguns elementos como, por exemplo, a imagem das crianças "raspando os tachos" onde eram preparados os doces como "o melado de rapadura", doce feito a partir da cana de açúcar que, embora conhecido nos Estados Unidos pelo próprio nome "rapadura"3 e originário das Ilhas Canárias no século XVI, é típico do nordeste do Brasil e de algumas regiões da América Latina; e "o cheiro de biscoito frito", quitute típico da culinária mineira, geralmente servido com café, ambos com aroma bastante forte e característico.

Ponciá Vicêncio traz ainda fatos históricos relacionados à questão da negritude no Brasil como a Lei Áurea, a Lei do Ventre Livre e a situação dos negros no período pré e pós-abolicionista. Segundo Duarte,

[a] ausência de cidadania que assinala a condição da maioria dos afro-brasileiros é marca constitutiva não só do enredo, mas da própria identidade da protagonista, pois o Vicêncio que lhe serve de nome provém diretamente do antigo senhor de seus ancestrais. (2011, p. 209)

Em alguns dos flashbacks apresentados pela voz narrativa, o romance retorna às terras do Coronel Vicêncio, dono dos escravos avós de Ponciá, e mostra o avô da menina enlouquecido ao ver que, mesmo após

\footnotetext{
Desde 2006 o Brasil vem lutando contra uma empresa alemã que patenteou a rapadura nos Estados Unidos (1993) e na Alemanha (1989). Mais informações ver: <http://www.estadao.com.br/noticias/ impresso,oab-tenta-anular-patente-da-marca-rapadura-na-alemanha-enos-eua, 153513,0.htm>.
} 
a Lei do Ventre Livre, filhos de escravos supostamente libertos continuavam sendo vendidos.

Vô Vicêncio com a mulher e os filhos viviam anos e anos nessa lida. Três ou quatro dos seus, nascidos do "ventre livre", entretanto, como muitos outros, tinham sido vendidos. Numa noite, o desespero venceu. Vô Vicêncio matou a mulher e tentou acabar com a própria vida. Armado com a mesma foice que lançara contra a mulher, começou a se autoflagelar decepando a mão. Acudido, é impedido de continuar o intento. Estava louco, chorando e rindo. Não morreu o Vô Vicêncio, a vida continuou com ele, independentemente do seu querer. Quiseram vendê-lo. Mas quem compraria um escravo louco e com o braço cotó? Tornou-se um estorvo para seus senhores. (EVARISTO, 2006, p. 51)

Ponciá Vicêncio mostra "a crueldade do cotidiano dos excluídos" (DUARTE, 2011, p. 208) através de memórias individuais e coletivas que recuperam traços da cultura e da história afro-brasileira, questionando registros e relatos hegemônicos. O romance também valoriza a cultura afro-brasileira, assim como a brasileira de um modo mais amplo, trazendo elementos como a religião - com diversas menções ao Candomblé, religião comumente praticada entre os afro-brasileiros; alimentos da culinária local e o próprio conceito de favela, que merece atenção especial por ser, por exemplo, bastante diferente da ideia de gueto nos Estados Unidos.

Certamente, as características aqui discutidas se apresentam como desafios na hora de se traduzir produções literárias como as de Morrison e Evaristo, pois muitos dos objetos, comidas típicas, paisagens, dialetos, dentre outros elementos utilizados pelas escritoras, não possuem um equivalente na cultura de chegada, exigindo uma escolha cuidadosa por parte do tradutor.

\section{Considerações Finais}

Mesmo que as culturas das Américas possuam suas especificidades, é possível observarmos algumas de suas relações no que se refere ao contexto da diáspora africana, por exemplo. E a literatura é um dos diversos campos em que tais diálogos estão presentes. Conforme observamos no presente artigo, as produções literárias de Toni Morrison e Conceição Evaristo buscam dar voz ao povo negro, embora em diferentes contextos das Américas, subvertendo a história oficial, eivada pelo preconceito racial e por tentativas de esconder ou apagar a identidade afrodescendente.

Traduzir elementos culturais é sempre uma tarefa muito delicada e, por essa razão, encontramos muitos registros dessa discussão na literatura dos estudos de tradução, tanto entre teóricos como entre tradutores (FERNANDES, 1988; AIXELÁ, 1996; LANDERS,
2001; VENUTI, 2010; VALENTE, 2013; SILVA, 2015). É comum nos depararmos, nos Estudos da Tradução, com questões como: o que fazer diante de questões complexas e cheias de implicações presentes no texto a ser traduzido, quais são as opções do tradutor enquanto mediador, quais são os prós e os contras de cada possibilidade de escolha, como tratar os elementos sem correspondentes na língua alvo, qual o efeito causado pelas escolhas do tradutor no leitor da tradução, entre outras, as quais são frequentemente encontradas em trabalhos dessa área (VALENTE, 2013, p. 91).

O fato é que essas são questões desafiadoras, difíceis de resolver e que estão relacionadas ao projeto tradutório e ao comprometimento do tradutor com a obra que está traduzindo. No caso das literaturas afrodescendentes nas Américas, independentemente da língua em que sejam escritas, esses elementos culturais são itens de grande importância, uma vez que fazem parte do universo de um povo historicamente subjugado e relegado à marginalidade e revelam uma postura de resistência ao padrão branco e eurocêntrico por parte de autoras como Morrison e Evaristo. "[À] imagem de Toni Morrison nos Estados Unidos, o trabalho de Conceição Evaristo é um exemplo perfeito de como a literatura pode ajudar a compreender melhor um país e a luta de um povo por reconhecimento" (ANACAONA, 2015, s.n.p. - tradução nossa). Nesse sentido, considerando o papel social, político e ideológico da literatura, no continente americano em particular, acreditamos que a manutenção de tais marcas e elementos culturais no processo de tradução seja fundamental para que a visibilidade dos afrodescendentes, nos mais diversos contextos relativos às Américas, seja cada vez mais crescente no mundo contemporâneo.

\section{Referências}

AIXELÁ, Javier Franco. Culture-specific Items in Translation. In: ALVAREZ, Román; VIDAL, Carmen-África (Eds.). Translation, Power, Subversion. Clevedon: Multilingual Matters, 1996.

ANACAONA, Paula. L'histoire de Ponciá. ActuaLitté: les univers du livre, 13 mar. 2015. Disponível em: <https://www. actualitte.com/communiques/1-histoire-de-poncia-2034.htm>. Acesso em: 14 mar. 2015.

BROCKES, Emma. Toni Morrison: "I Want to Feel What I Feel. Even If It's Not Happiness". The Guardian Online, Reino Unido, 13 abr. 2012. Disponível em: <http://www.theguardian. com/books/2012/apr/13/toni-morrison-home-son-love $>$. Acesso em: 30 fev. 2015.

DUARTE, Eduardo de Assis (Org.). Literatura e afrodescendência no Brasil: antologia crítica. Belo Horizonte: Editora UFMG, 2011. Vol. 2 (a). 2013.

EVARISTO, Conceição. Ponciá Vicêncio. Belo Horizonte: Mazza, 2003. 
EVARISTO, Conceição. Ponciá Vicêncio. 2. ed. Belo Horizonte: Mazza, 2006.

EVARISTO, Conceição. Da grafia-desenho de minha mãe, um dos lugares de nascimento de mi-nha escrita. In: ALEXANDRE, Marcos Antônio (Org.). Representações performáticas brasileiras: teorias, práticas e suas interfaces. Belo Horizonte: Mazza, 2007.

EVARISTO, Conceição. Ponciá Vicêncio. Traduzido por Paloma Martinez-Cruz. Texas: Host-Publications, 2007.

FERNANDES, Millôr. The cow went to the swamp ou A vaca foi pro brejo. 9. ed. Rio de Janeiro: Record, 1988.

GATES, Henry L. Jr.; MCKAY, Nellie Y. (Orgs.). The Norton Anthology of African American Literature. New York: W. W. Norton, 1997.

GATES, Henry L. Jr. The Signifying Monkey: A Theory of African American Literary Criticism. New York; Oxford: Oxford University Press, 1989.

GENTZLER, Edwin. Translation Without Borders. Translation: A Transdisciplinary Journal, v. 1., n. 1., 2014. Disponível em: $<$ http://translation.fusp.it/articles/translation-without-borders $>$. Acesso em: 20 fev. 2015.

HACKNEY, Sheldon. I Come From People Who Sang All Time: A Conversation With Toni Morrison. 1996. In: DENARD, Carolyn (Org.). Toni Morrison: Conversations. Jackson: University Press of Mississippi, 2008. p. 126-138.

HOUSTON, Pam. Pam Houston Talks With Toni Morrison. 2005. In: DENARD, Carolyn (Org.). Toni Morrison: Conversations. Jackson: University Press of Mississippi, 2008. p. 228-259.

LANDERS, Clifford. Literary Traslation: a practical guide. Clevedon: Multilingual Matters: 2001.

LIMA, Omar da Silva. O comprometimento etnográfico afrodescendente das escritoras negras Conceição Evaristo \& Geni Guimarães. 2009. 172p. Tese (Doutorado em Literatura
Brasileira) - Departamento de Teoria Literária e Literatura, Universidade de Brasília.

LUCCHESI, Dante; BAXTER, Alan; RIBEIRO, Ilza (Orgs.). O português afro-brasileiro. Salvador: EDUFBA, 2009.

MORRISON, Toni . Beloved. New York: Vintage Books, 2004.

MORRISON, Toni. Amada. Tradução de José Rubens Siqueira. São Paulo: Companhia das Letras, 2007.

NEVES, Lucas. Negra em Salão do Livro causa furor, diz autora brasileira. In: Folha de são Paulo. 23 mar. 2015. Disponível em: $<$ http://www1.folha.uol.com.br/ilustrada/2015/03/1606652negra-em-salao-do-livro-causa-furor-diz-autora-brasileira. shtml>. Acesso em: 30 mar. 2015.

RUSHDIE, Salman. An Interview with Toni Morrison. 1992. In: DENARD, Carolyn (Org.). Toni Morrison: Conversations. Jackson: University Press of Mississippi, 2008. p. 51-61.

SILVA, Luciana de Mesquita. Literatura traduzida em foco: Toni Morrison e Beloved no contexto cultural brasileiro. 2015. 202p. Tese (Doutorado em Letras - Estudos da Linguagem) Departamento de Letras, Pontifícia Universidade Católica do Rio de Janeiro.

VALENTE, Marcela Iochem. A tradução e a construção de imagens culturais: Ponciá Vicêncio, de Conceição Evaristo, e sua tradução para o inglês. 2013. 162p. Tese (Doutorado em Estudos Letras - da Linguagem) - Departamento de Letras, Pontifícia Universidade Católica do Rio de Janeiro.

VENUTI, Lawrence. Translation as Cultural Politics: Régimes of domestication in English. In: BAKER, Mona (Ed.). Critical Readings in Translation Studies. London and New York: Routledge, 2010. p. 65-79.

Recebido: 14 de abril de 2015

Aprovado: 02 de julho de 2015

Contatos:marcellaiv@ig.com.br lusincera@yahoo.com.br 